\title{
Determination of Antioxidant and Antimicrobial Activities of Medically Important Mushrooms Using Different Solvents and Chemical Composition via GC/MS Analyses
}

\author{
Emre Avcı ${ }^{1}$, Gulcin Alp Avci ${ }^{2, *}$, Dursun Ali Kose ${ }^{3}$ \\ ${ }^{1}$ Department Molecular Biology and Genetics/Biochemistry, Hitit University, Corum, Turkey \\ ${ }^{2}$ Department Molecular Biology and Genetics/ Molecular Microbiology, Hitit University, Corum, Turkey \\ ${ }^{3}$ Department Chemistry, Hitit University, Corum, Turkey \\ *Corresponding author: gulcinalp@hitit.edu.tr
}

Received July 04, 2014; Revised July 23, 2014; Accepted July 28, 2014

\begin{abstract}
The aim of present work was the determination of antioxidant activities of the ethanol extract from three mushrooms (Ganoderma lucidium, Lentinula edodes and Coprinus micaceus) by using DPPH radical scavenging and total antioxidant status assays. Additionally, in this study, GC/MS analyses and antimicrobial activity assay of three mushrooms were made. Ethanol, chloroform and distilled water used as solvent for preparation of mushrooms extract. Radical scavenging activities and total antioxidant status of three mushrooms extracted in ethanol were measured via spectrophotometric methods. In addition, for chromatographic analysis GC/MS were used. At the same time, diphenic acid and bis(2-ethylhexyl)pthalate derivatives were found the highest in contents of all extracts with GC/MS. The determination of antimicrobial activity of mushrooms extracts against Pseudomonas aeroginosa (ATCC 27853), Escherichia coli (ATCC 25922), Enterococcus faecalis (ATCC 29212), Staphylococcus aureus (ATCC 25923) and Candida albicans (ATCC 10231) was investigated by disc and agar-well diffusion methods. As result, radical scavenging activities and total antioxidant status values of $G$. lucidium extract were found higher than those of both $L$. edodes and C. micaceus. All mushrooms used in this study were found to have antimicrobial effects at a variety of degrees against microorganisms tested. Moreover, all extracts together with solvents were analyzed, ethanol and chloroform extracts were found to be more effective for G. lucidum and C. micaceus, and L. edodes than other solvents, respectively.
\end{abstract}

Keywords: Ganoderma lucidium, Lentinula edodes, Coprinus micaceus, radical scavenging activity, total antioxidant status, GC/MS analysis, antimicrobial activity

Cite This Article: Emre Avc1, Gulcin Alp Avc1, and Dursun Ali Kose, "Different Solvents and Chemical Composition via GC/MS Analyses.” Journal of Food and Nutrition Research, vol. 2, no. 8 (2014): 429-434. doi: 10.12691/jfnr-2-8-1.

\section{Introduction}

Mushrooms are well known in terms of their medicinal importance and have long been used in traditional medicines in many parts of the world. Mushrooms are one of the major sources of natural products exhibiting bioactivities including antimicrobial and antiviral activities [1]. Ganoderma lucidium can not be used in daily diet whereas Lentinula edodes and Coprinus micaceus can be used as nutrient because of their medical effects.

Reishi (G. lucidium) is a popular medicinal and have many biologically active components like triterpenoids, polysaccharides, ganoderic acid and so on, giving it, its antimicrobial, antioxidant, antiviral and anticancer properties [2]. Like many plants, mushrooms protect organisms against oxidative stress and thus they can be considered as antioxidants which play an important role for chemoprevention of diseases caused by reactive oxygen species [2,3]. Mushrooms have antioxidant activity which is medically significant due to containing particularly vitamins $\mathrm{A}$ and $\mathrm{C}$, beta-carotenes and secondary metabolites such as phenolic compounds, steroids and terpenes. [3]. Shiitake ( $L$. edodes) is the second largest cultivated and most popular mushroom in world [4]. Shiitake have several functional properties such as antitumor and hypocholesterolemic effects, and antimicrobial and antioxidant features that have been intensively investigated $[5,6]$. Shiitake mushrooms are the main sources of some antioxidant minerals. Polyphenolic compounds have also been detected in shiitake, and may contribute to the antioxidant potential of this kind of mushroom [7]. C. micaceus belongs to the genus of Coprinus - medically important mushrooms- which is easy to cultivate and excellent in flavor. Extracts from several members of the genus Coprinus are known in 
many parts of the world as compared to others due to their antimicrobial, antioxidant, antitumor and hypoglycemic effects [8]. Although C. micaceus is one of the famous mushrooms in the world in terms of medical effect, there was no or few scientific study.

The main objectives of this study were (i) to investigate the antimicrobial activity of three mushrooms extracts prepared using three different solvents through agar-well diffusion and disc diffusion methods for Pseudomonas aeroginosa (ATCC 27853), Escherichia coli (ATCC 25922), Enterococcus faecalis (ATCC 29212), Staphylococcus aureus (ATCC 25923) and Candida albicans (ATCC 10231), (ii) to determine the chemical composition of extracts using GC/MS and (iii) to evaluate radical scavenging effects and total antioxidant status.

\section{Material and Methods}

\subsection{Collection and Identification of Mushroom Samples}

C. micaceus (Bull.: Fr) samples were collected from Uğurludag region, Corum, Turkey. Identification of $C$. micaceus samples was confirmed by taxonomist Dr. Adem Imali from the Department of Biology, Kilis 7 Aralık University, Turkey. Reishi and Shiitake samples were obtained commercially.

\subsection{Preparation of Mushroom Extracts}

After C. micaceus samples were collected, samples were dried at room temperature (RT) for a week. Dried $C$. micaceus samples, reishii and shiitake purchased commercially were grounded in a grinder using a $2 \mathrm{~mm}$ diameter mesh before the extractions. Approximately $25 \mathrm{~g}$ of dried and powdered samples were extracted using ethanol, chloroform and water (ultra-pure) via Soxhlet apparatus at $60^{\circ} \mathrm{C}$ for 6 hours. Extracts obtained were filtered and then concentrated under $75^{\circ} \mathrm{C}$ using rotary evaporator (Millipore, Hong Kong). Extracts were stored at $4^{\circ} \mathrm{C}$ until used within a maximum period of a week.

\subsection{Determination of Antioxidant Activity}

\subsubsection{DPPH Radical Scavenging Assay}

Radical scavenging activity was determined via a spectrophotometric method based on the reduction of an ethanol solution of DPPH using the modification method developed by Blois (1958) and Khalaf (2008) [9,10]. A milliliter of different concentrations of extract in ethanol was added to $1 \mathrm{ml}$ of a $0.004 \%$ methanol solution of $\mathrm{DPPH}$. The mixture was shaken vigorously and allowed to stand at room temperature for 30 min in dark environment. Then the absorbance was measured at $517 \mathrm{~nm}$ against a blank by a spectrophotometer (Biochrom Libra, USA). Inhibition ratio (\%) of free radical, DPPH, was calculated according to formula given below:

$$
I D A \%=\frac{\text { Ablank }- \text { Asample }}{\text { Ablank }} \times 100
$$

IDA; Inhibition of DPPH activity

$A_{\text {blank }}$ is the absorbance of the control reaction (containing all reagents except test compound), and $\mathrm{A}_{\text {sample }}$ is the absorbance of test compound. Concentration of extract with $50 \%$ inhibition $\left(\mathrm{IC}_{50}\right.$ ) was calculated from the graph of inhibition percentage versus concentration of extract. Tests were repeated three times. Ascorbic acid was used as positive control.

\subsubsection{Total Antioxidant Status assay}

The total antioxidant status (TAS) of the mushroom extracts was determined using a novel automated colorimetric measurement method developed by Erel (2004) [11]. In this method, a hydroxyl radical was produced by the Fenton reaction and reacted with colorless substrate o-dianisidine to produce the bright yellowish-brown dianisyl radical. Results were expressed as micromolar Trolox equivalents per liter ( $\mu$ mol Trolox $\mathrm{Eq} / \mathrm{L})$.

\subsubsection{Gas Chromatography/mass Spectrometry (GC/MS) Analysis}

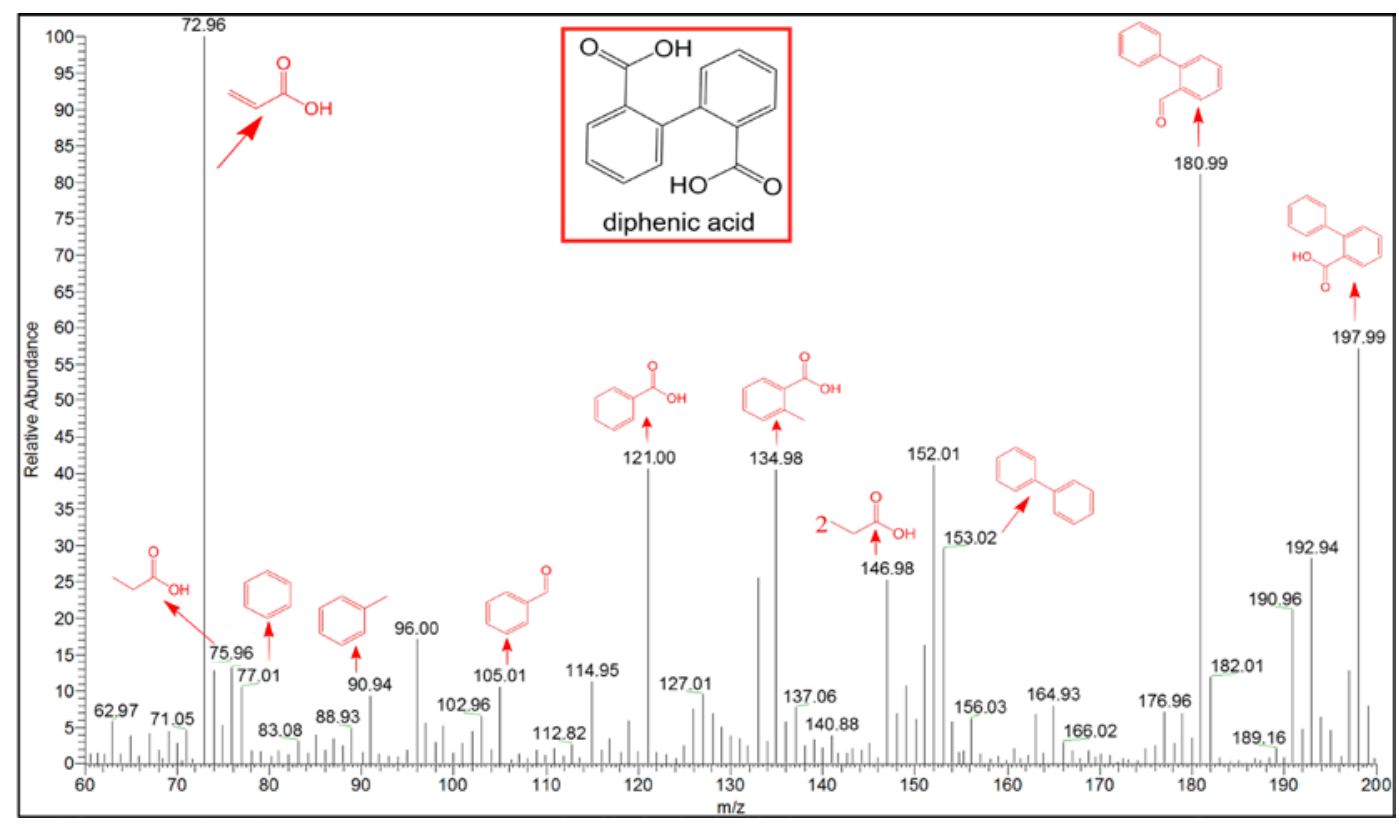

Figure 1. GC/MS spectra and fragmentation patterns of diphenic acid 
Chemical compositions of plant extracts were analyzed by using GC/MS technique and so fragmentation analysis was performed (Figure 1 and Figure 2). Thermo Scientific DSQ II Single Quadrupole GC/MS was used on the electron impact (EI) ionisation mode (70 eV) and HP$5 \mathrm{MS}$ (bonded and cross-linked 5\% phenylmethylpolysiloxane, $30 \mathrm{~mm}$ x $0.25 \mathrm{~mm}$, coating thickness $0.25 \mu \mathrm{m})$ capillary column (Restek, Bellefonte, PA). Injector and detector temperatures were set at $220^{\circ} \mathrm{C}$. Oven temperature was held at $50^{\circ} \mathrm{C}$ for $30 \mathrm{~min}$, then elevated to $240^{\circ} \mathrm{C}$ at the rate of $3^{\circ} \mathrm{C} / \mathrm{min}$. Helium (99.99\%) was the carrier gas at a flow rate of $1 \mathrm{ml} / \mathrm{min}$. The molecular weight of decomposition products were performed at the scan range of $60-200 \mathrm{~g} / \mathrm{mol}$. Diluted samples $(1 / 100$ in chloroform, $v / v)$ of $1.0 \mu \mathrm{L}$ were injected manually. The identification of components was conducted according to the comparison of their mass spectra with those of Wiley $7 \mathrm{~N}$ (contains 392.086 compounds spectra), Nist 2002 (contains 174.948 compounds spectra) and flavor (contains 419 compounds spectra) libraries and as well as by comparison of their retention times.

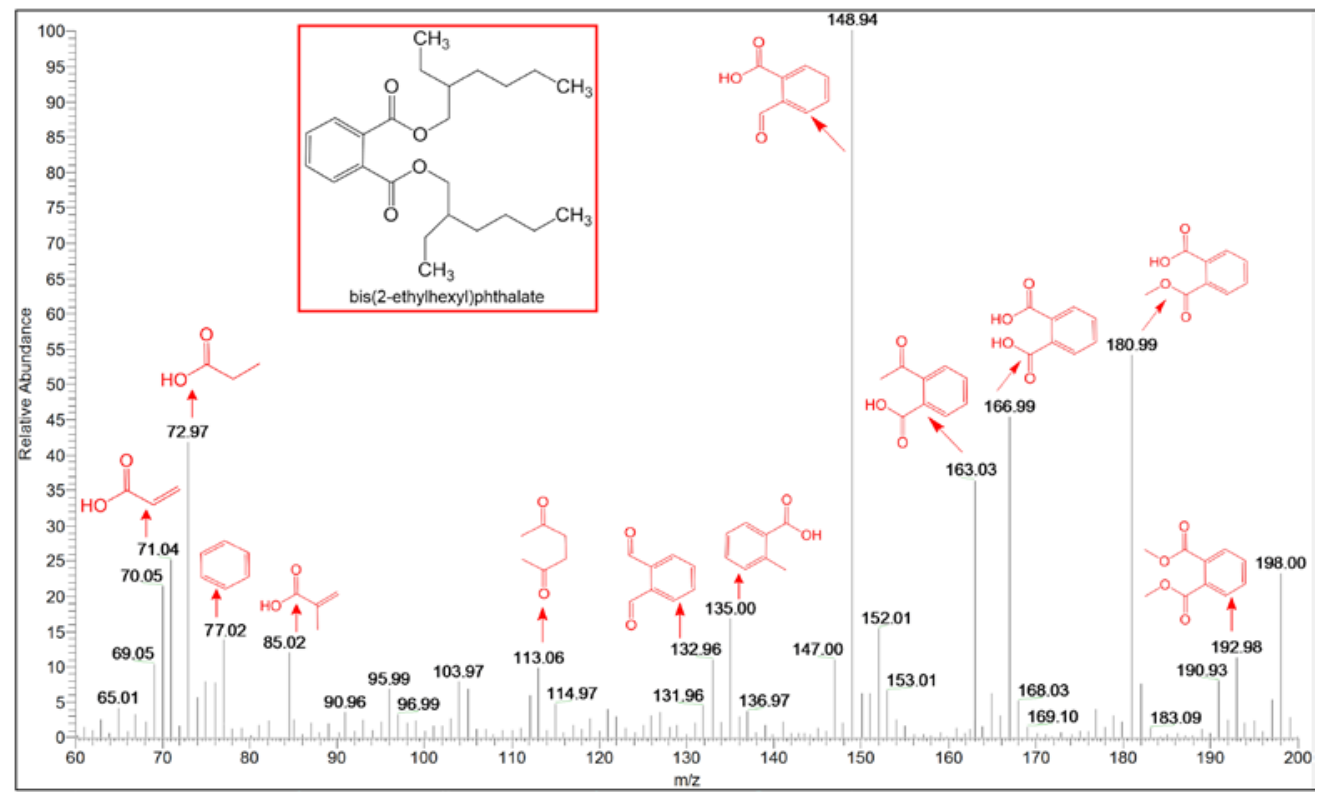

Figure 2. GC/MS spectra and fragmentation patterns of bis(2-ethylexyl)phatalate

\subsection{Determination of Antimicrobial Activity}

\subsubsection{Organisms and Growth Conditions}

Activities of mushrooms dissolved in ethanol, chloroform and water were investigated against microorganisms. Bacterial cultures of Enterecoccus faecalis ATCC 29212, Escherichia coli ATCC 25922 Staphylococcus aureus ATCC 25923 and fungal culture of Candida albicans ATCC 10231 were obtained from the culture collection at Hitit University, Faculty of Science and Arts, Departments of Molecular Biology and Genetics / Molecular Microbiology. In this study, nutrient broth and agar (Diffco) for E. coli cultures; Tryptone-Yeast extractCystine (TYC) broth and agar for E. fecalis and S. aureus cultures; Eosin Methylene Blue (EMB, Merck) broth and agar for $P$. aeroginosa cultures and Sabouraud Dextrose broth and agar (SD, Merck) for C. albicans cultures were used for growth of microorganisms. All strains stored at $20^{\circ} \mathrm{C}$ in appropriate medium containing $10 \%$ glycerol and regenerated twice before use.

\subsubsection{Agar-well and Disc Diffusion Method}

The antimicrobial activity of mushrooms extracts was determined through disc and agar-well diffusion methods. In antimicrobial studies, Mueller Hinton Agar (MHA) was used as media. Bacterial cultures were grown at $37^{\circ} \mathrm{C}$ for 24 hours in a nutrient broth and $C$. albicans was grown at $25^{\circ} \mathrm{C}$ for 48 hours in sabouraud dextrose. Culture suspensions were adjusted by comparison against McFarland 0.5 standard (1-5×10 6 CFU/mL). Petri dishes with $10 \mathrm{~mL}$ MHA were prepared after inoculation with culture suspension of $100 \mu \mathrm{l} .15 \mu \mathrm{L}$ of extracts dissolved previously within respective solvents (ethanol, chloroform and water) were poured into 6-mm agar-well and/or discs prepared using paper (Watman no. 4). In addition, an equal volume (15 $\mu \mathrm{l}$ for agar-well and $15 \mu \mathrm{l}$ for disc) of each solvent (ethanol, chloroform and water) was used as control. Plates inoculated were incubated for 24 hours $(C$. albicans for 48 hours). After incubation, diameter of the inhibition zone was measured from the edge of the zone to the edge of the well or the disc by using calipers.

\subsection{Statistical Analysis}

All experiments were conducted three times. Results were obtained via calculation average values. Statistical analysis of data was performed through SPSS 15.0 Bivariate Correlation Analysis (SPSS Inc., Chicago) with statistical significance determined at 0.05 . The Pearson rank correlation test was used for comparisons between disc and agar-well diffusion methods to determine the antimicrobial activity of extracts. According to inhibition zones of extracts for microorganisms, there was no significant correlation observed for these two methods ( $>0.05)$. Moreover, significance between mean values for two methods was analyzed according to the MannWhitney U tests, and also was compared with Levene's test and T-test for equality of means for independent groups. 


\section{Results and Discussion}

Since antioxidant and/or antimicrobial activities found in plants have different polarities, different solvents were used to determine antioxidant and/or antimicrobial activities. Water, methanol, ethanol, acetone, and dimethyle sulfoxide (DMSO) are solvents commonly used for extraction processes. Antioxidant and/or antimicrobial activities of extract and yield depend on the solvent selected [12,13]. In this study ethanol, chloroform and distilled water were preferred to be prepared as solvents for Reishi, Shiitake and C. micaceus extracts. Ethanol extracts were investigated to determine radical scavenging activity and total antioxidant status of mushrooms. In addition, antimicrobial activities of all mushrooms extracts were determined.

\subsection{Determination of Antioxidant Activity}

Free radical scavenging activity was investigated for DPPH assay. IC $_{50}$ values for DPPH scavenging activities of mushrooms extracts and ascorbic acid were compared and shown at Table 1 . The highest DPPH radical scavenging effect was detected for Reishi extract (RE, $\left.\mathrm{IC}_{50}=32.0 \mathrm{mg} / \mathrm{ml}\right)$. Shiitake and $C$. micaceus extracts exhibited weak radical scavenging effect $\left(\mathrm{SE}, \mathrm{IC}_{50}=24.6\right.$ $\mathrm{mg} / \mathrm{ml}$ and $\mathrm{CME}, \mathrm{IC}_{50}=18.2 \mathrm{mg} / \mathrm{ml}$ ). According to the results, Reishi extracts have more effective scavenging ability for DPPH radicals than for other mushrooms extracts. Fu et al. (2002) has reported that DPPH radical scavenging activity of ethanol extract of $P$. eryngii is $15.2 \%$ at $400 \mu \mathrm{g} / \mathrm{ml}$ [14]. DPPH radical scavenging activity of methanol extract of $P$. eryngii was $21.9 \%$ at $400 \mathrm{lg} / \mathrm{ml}$. DPPH scavenging abilities of ethanol extracts of $P$. eryngii were found in the range of $78.7-92.2 \%$ at $10-20 \mathrm{mg} / \mathrm{ml}[15]$.

Table 1. DPPH radical scavenging and antioxidant activities of mushrooms ethanol extracts

\begin{tabular}{|c|c|c|}
\hline Ethanol extracts & DPPH IC $_{50}$ & TAS \\
\hline Reishi (G. lucidium) & 32.0 & 9.24 \\
\hline Shiitake (L. edodes) & 24.6 & 5.89 \\
\hline C. micaceus & 18.2 & 3.64 \\
\hline Ascorbic acid & 34.6 & NS \\
\hline
\end{tabular}

Values was represented as mean \pm standard deviations for triplicate experiments.

Total antioxidant activity was measured as mmol Trolox Equiv./L DPPH IC ${ }_{50}$ was measured as $\mu \mathrm{g} / \mathrm{ml}$

NS; not studied

In this study, antioxidant activity of an ethanol extract of three mushrooms was measured spectrophotometrically using assay kit. Total antioxidant status (TAS) values for ethanol extracts of three different mushrooms are given by Table 1. According to table, ethanol extracts were observed to have total antioxidant status. Moreover, TAS values of Reishi extract was higher than those of both Shiitake and $C$. micaceus. There are studies in the literature reporting different rate of radical scavenging and total antioxidant activity of medically important plants $[16,17]$. Furthermore, it was observed that total antioxidant status of Reishi and Shiitake ethanol extracts have had positive correlation (in order of $r=0.753$ and $\mathrm{r}=0.391$ ) with their antimicrobial activities for disc diffusion method.

\subsection{GC/MS Analysis}

Diphenic acid and bis(2-ethylexyl) phatalate were common components used for GC/MS analysis. In addition, other molecules such as 4-phenylbenzoylchloride, 5-methoxycyclooctanol, 2-oxo-dodecanoic acid ethylester, phenyl benzoyl chloride were observed within the structure of mushroom samples.

\subsection{Antimicrobial Activity of Mushroom Extracts}

In this work, antimicrobial activity of three different mushrooms prepared at three different solvent was tested against two species of gram positive bacteria ( $S$. aureus ATCC 25923 and E. faecalis ATCC 29212), two species of gram negative bacteria ( $P$. aeruginosa ATCC 27853 and E. coli ATCC 25922) and one species of fungi ( $C$. albicans ATCC 10231). All extracts together with solvents were analyzed. Ethanol extract of Reishi and $C$. micaceus, chloroform extract of Shiitake were more effective than those of other solvents. Although antimicrobial activity determined at different rate for microorganisms of ethanol and chloroform extracts for both disc diffusion and agar-well diffusion method, it was determined only at much lower rate for distilled water extracts of Shiitake. All mushrooms used in this study were found to have various degrees of antimicrobial effects against microorganisms tested (Figure 3).

Antimicrobial activity results of mushrooms extracts are summarized by disc and agar-well diffusion methods at Table 2 and 3. Results of disc diffusion method in terms of size of inhibition zone $(\mathrm{mm})$ for the extracts were compared against microorganisms studied. For Reishi extracts, the highest inhibitory activity was determined against $E$. faecalis ATCC 29212 (inhibition zone diameter 16.0 for ethanol extracts and 17.0 for chloroform extracts). However, for the same extracts, the weakest inhibitory activity was determined against $P$. aeruginosa ATCC 27853 (inhibition zone diameter 6.5 for ethanol extracts and 5.5 for chloroform extracts). In addition, C. albicans ATCC 10231 (inhibition zone diameter 14.5 for ethanol extracts and 19.0 for chloroform extracts) was found as the most sensitive microorganisms against Shiitake extracts, and the $P$. aeruginosa ATCC 27853 (inhibition zone diameter 5.0 for ethanol extracts and 6.5 for chloroform extracts) was found as the most resistive microorganisms against Shiitake extracts. However, E. faecalis ATCC 29212 (inhibition zone diameter 6.0 for ethanol extracts and 4.5 for chloroform extracts) was found as the most resistive microorganisms against $C$. micaceus extracts, and $P$. aeruginosa ATCC 27853 (inhibition zone diameter 11.0 for ethanol extracts and 8.0 for chloroform extracts) was found as the most sensitive microorganisms against $C$. micaceus extracts.

The results of antibacterial activity of mushrooms extracts were presented at Table 2 and Table 3. In the case of comparison of results of the two diffusion methods, similar results were found for our works. The highest inhibitory activity was determined against E. faecalis ATCC ATCC 29212. E. faecalis ATCC ATCC 29212 (inhibition zone diameter 14.0 for ethanol extracts and 13.0 for chloroform extracts) was found as the most sensitive microorganisms against Reishi extracts, and $P$. aeruginosa ATCC ATCC 27853 (inhibition zone diameter 
8.5 for ethanol extracts and 8.0 for chloroform extracts) was found as the most resistive microorganisms against Reishi extracts. In addition, C. albicans ATCC ATCC 10231 (inhibition zone diameter 12.5 for ethanol extracts and 15.5 for chloroform extracts) was found as the most sensitive microorganisms against Shiitake extracts, and E. coli ATCC ATCC 25922 (inhibition zone diameter 8.0 for ethanol extracts and 10.0 for chloroform extracts) was found as the most resistive microorganisms against Shiitake extracts. However, E. faecalis ATCC ATCC 29212 (inhibition zone diameter 8.5 for ethanol extracts and 7.0 for chloroform extracts) was found as the most resistive microorganisms against $C$. micaceus extracts, and P. aeruginosa ATCC ATCC 27853 (inhibition zone diameter 12.0 for ethanol extracts and 10.0 for chloroform extracts) was found as the most sensitive microorganisms against $C$. micaceus extracts. There was no statistically significant difference observed between ethanol and chloroform extracts of Reishi ( $>>0.05)$. Nevertheless, there was statistically significant correlation observed between ethanol and chloroform extracts of both Shiitake and C. micaceus $(\mathrm{p}<0.05)$. Researchers has showed the antimicrobial activity of several mushrooms $[18,19,20]$. In recent years, multiple drug resistance for human pathogenic microorganisms has been developed due to indiscriminate use of commercial antimicrobial drugs commonly used in the treatment of infectious diseases. This situation has forced scientists to investigate new antimicrobial substances obtained from various sources of novel antimicrobial chemotherapeutic agents [21]. In the study of Mondal et al. (2013), scientifically examined Reishi and certain mushrooms have had antioxidant and antimicrobial (antibacterial and antifungal) properties [22]. These mushrooms were much effective against bacteria such as S. aureus, E. coli through agar-well diffusion method. Additionally, antifungal activity was shown for these mushrooms extracts. Results indicate that all mushroom mentioned above have antimicrobial and antioxidant properties. On the other hand, Shiitake mushrooms had antimicrobial activities against Grampositive and Gram negative bacteria as described previously by many authors $[23,24]$.

Table 2. Antimicrobial activities of mushrooms extracts for disk diffusion method

\begin{tabular}{|c|c|c|c|c|c|}
\hline \multirow{2}{*}{$\begin{array}{c}\text { Extracts of } \\
\text { mushrooms }\end{array}$} & \multicolumn{5}{c|}{ Strains (Inhibiton zone diameter (mm \pm SD) } \\
\cline { 2 - 6 } & $\begin{array}{c}\text { S. } \\
\text { aureus }\end{array}$ & $\begin{array}{c}E . \\
\text { faecalis }\end{array}$ & $\begin{array}{c}P . \\
\text { aeruginosa }\end{array}$ & $\begin{array}{c}E . \\
\text { coli }\end{array}$ & $\begin{array}{c}C . \\
\text { albicans }\end{array}$ \\
\hline Ganoderma lucidium \\
\hline *Ethanol & 14.0 & 16.0 & 6.5 & 9.5 & 14.5 \\
\hline *Chloroform & 10.5 & 17.0 & 5.5 & 7.5 & 16.5 \\
\hline DW & ND & ND & ND & ND & ND \\
\hline \multicolumn{7}{|c|}{ Lentinula edodes } \\
\hline *Ethanol & 11.0 & 8.0 & 5.0 & 12.0 & 14.5 \\
\hline *Chloroform & 12.5 & 9.0 & 6.5 & 14.0 & 19.0 \\
\hline DW & ND & ND & ND & ND & ND \\
\hline \multicolumn{7}{|c|}{ Coprinus micaceus } \\
\hline *Ethanol & 6.5 & 6.0 & 11.0 & 10.5 & 8.0 \\
\hline *Chloroform & 5.0 & 4.5 & 8.0 & 7.0 & 6.0 \\
\hline DW & ND & ND & ND & ND & ND \\
\hline \multicolumn{7}{|c|}{ Antibiotic Disc } \\
\hline Chloramphenicol & 20.0 & 18.0 & 18.0 & 24.0 & ND \\
\hline Streptomycin & 14.0 & 10.0 & 18.0 & 16.0 & ND \\
\hline Fluconazole & ND & ND & ND & ND & 16.0 \\
\hline
\end{tabular}

DW, Distilled water; ND, not determined.

Values are expressed as mean \pm standard deviation.

${ }^{*} \mathrm{p}>0.05$, There is no statistically significant differences observed for two methods applied on test microorganisms for all mushrooms samples.
Table 3. Antimicrobial activities of mushrooms extracts for agarwell diffusion method

\begin{tabular}{|c|c|c|c|c|c|}
\hline \multirow{2}{*}{$\begin{array}{c}\text { Extracts of } \\
\text { mushroom }\end{array}$} & $\begin{array}{c}\text { S. } \\
\text { aureus }\end{array}$ & $\begin{array}{c}\text { E. } \\
\text { faecalis }\end{array}$ & $\begin{array}{c}\text { P. } \\
\text { aeruginosa }\end{array}$ & $\begin{array}{c}\text { E. } \\
\text { coli }\end{array}$ & $\begin{array}{c}\text { C. } \\
\text { albicans }\end{array}$ \\
\cline { 2 - 6 } & \multicolumn{6}{|c|}{ Ganoderma lucidium } \\
\hline *Ethanol & 9.5 & 14.0 & 8.5 & 13.0 & 13.5 \\
\hline *Chloroform & 8.5 & 13.0 & 8.0 & 11.5 & 12.0 \\
\hline DW & ND & ND & ND & ND & ND \\
\hline \multicolumn{7}{|c|}{ Lentinula edodes } \\
\hline *Ethanol & 10.0 & 9.0 & 12.0 & 8.0 & 12.5 \\
\hline *Chloroform & 13.5 & 14.5 & 15.0 & 10.0 & 15.5 \\
\hline DW & 3.0 & 5.5 & 3.5 & 5.0 & 4.0 \\
\hline \multicolumn{7}{|c|}{ Coprinus micaceus } \\
\hline *Ethanol & 9.0 & 8.5 & 12.0 & 11.5 & 10.0 \\
\hline *Chloroform & 7.5 & 7.0 & 10.0 & 9.0 & 8.0 \\
\hline DW & ND & ND & ND & ND & ND \\
\hline
\end{tabular}

DW, Distilled water; ND, not determined.

Values are expressed as mean \pm standard deviation.

${ }^{*} \mathrm{p}>0.05$, There is no statistically significant differences observed for two methods applied on test microorganisms for all mushrooms samples.

In conclusion, radical scavenging and antioxidant activities of Reishi extracts was found higher than those of both Shiitake and $C$. micaceus as a result of antioxidant studies. Moreover, all the mushrooms used in this study were found to have various degrees of antimicrobial effects against microorganisms tested. Additionally, two methods were compared with each other and agar-well diffusion method was found as a better method than disc diffusion method in terms of determination for this study. Considering the data obtained in this study that we basically were basically emphasized medical importance of these kind of mushrooms. However, in order to use these mushrooms properly in medicine, more detailed studies are needed to be conducted.

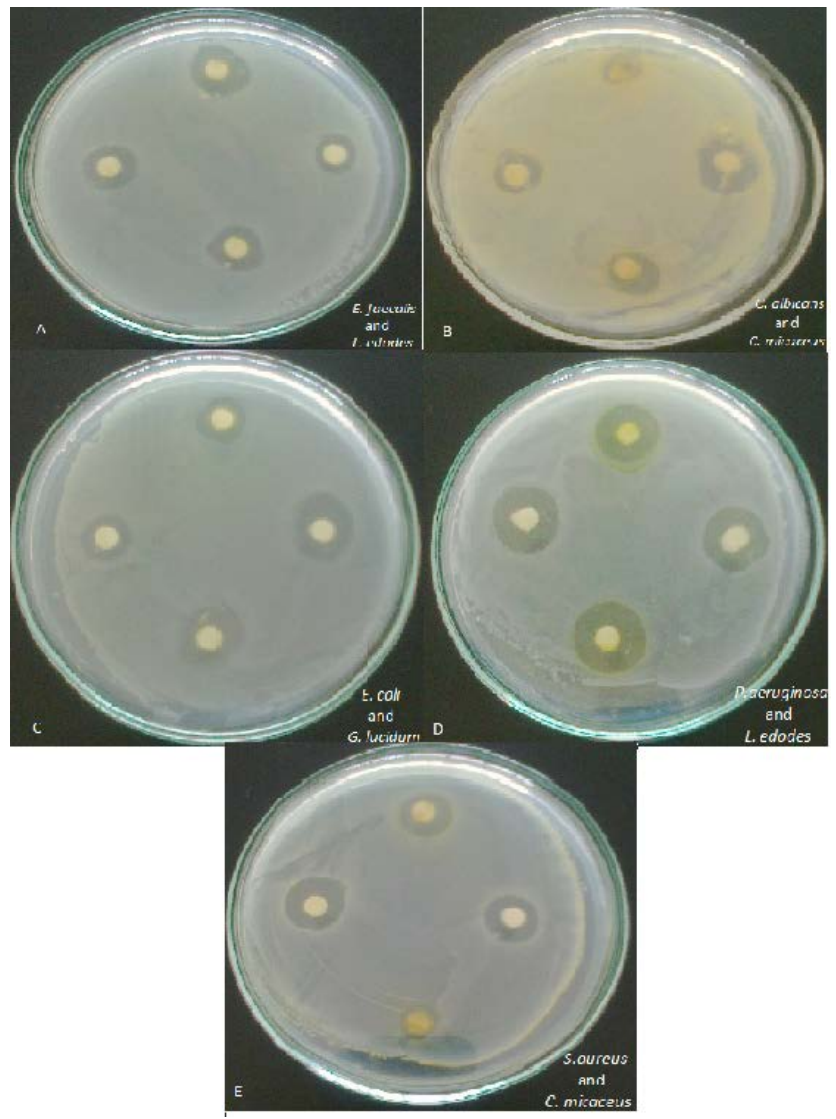

Figure 3. Sample pictures for antimicrobial activity studies (A. E. faecalis- L. edodes, B. C. albicans- C. micaceus, C. E. coli- G. lucidum, D. P. aeruginosa- L. edodes, E. S. aureus- C. micaceus) 


\section{Acknowledgments}

We are thankful to Department of Biology, Kilis 7 December University, Asosc. Prof. Adem IMALI for identification C. micaceus. This study was supported financially by Science Research Department of Hitit University, 2013 (SRD, FEF01.13.004).

\section{References}

[1] Zahid S, Udenigwe C.C, Ata A, Eze M.O, Segstro E.P, Holloway $\mathrm{P}$, “ New bioactive natural products from Coprinus micaceus”, Nat Pro Research, 20B (14). 1283-1289. 2006.

[2] Kamra A, Bhatt A.B, "Evaluation of antimicrobial and antioxidant activity of Ganoderma lucidum extracts against human pathogenic bacteria”, Inter J Pharm Pharm Sci, 4 (2). 359-361. 2012.

[3] Soares A.A, De Souza C.G.M, Daniel F.M, Ferrari G.P, da Costa S.M.G, Dan Peralta R.M, "Antioxidant activity and total phenolic content of Agaricus brasiliensis (Agaricus blazei Murril) in two stages of maturity”, Food Chem, 112 (4). 775-781. 2009.

[4] Kitzberger C.S, Smânia J.R, Pedrosa R.C, Ferreira S.R, "Antioxidant and antimicrobial activities of shiitake (Lentinula edodes) extracts obtained by organic solvents and supercritical fluids”, J Food Eng, 80. 631-638. 2007.

[5] Ng M.L, Yap A.T. "Inhibition of human colon carcinoma development by lentinan from shiitake mushrooms (Lentinus edodes)”, J Altern Complement Med, 8 (5). 581-589. 2002.

[6] Hearst R, Nelson D, McCollum G, Millar B.C, Maeda Y, Goldsmith C.E, Rooney, P.J., Loughrey, A., Rao, J.R, Moore, J.E., "An examination of antibacterial and antifungal properties of constituents of Shiitake (Lentinula edodes) and Oyster (Pleurotus ostreatus) mushrooms”, Complement Ther Clin Prac, 15 (1). 5-7. 2009.

[7] Zhang Z, Lv G, Pan H, Wu Y, Fan L, "Effects of different drying methods and extraction condition on antioxidant properties of Shiitake (Lentinus edodes)", Food Sci Technol Res, 15, 547-552. 2009.

[8] Ndyetabura T, Lyantagaye S.L, Mshandete A.M, “Antimicrobial activity of ethyl acetate extracts from edible tanzanian Coprinus cinereus (schaeff) s. Gray s.lat. Cultivated on grasses supplemented with cow dung manure”, Arpn J Agric Biol Sci, 5 (5). 79-85. 2010.

[9] Blois M.S, "Antioxidant determinations by the use of a stable free radical”, Nature, 181. 1199-1200. 1958.

[10] Khalaf A.N, Shakya A.K, Al-othman A, El-Agbar Z, Farah H, “Antioxidant Activity of Some Common Plants", Turk J Biol, 32. 51-55. 2008.
[11] Erel O, "A novel automated method to measure total antioxidant response against potent free radical reactions”, Clin Biochem. 37. 112-119. 2004

[12] Aslim B, Alp G, “The effect of immobilization on some probiotic properties of Streptococcus thermophilus strains”, Annal Micro, 59 (1). 127-132. 2009

[13] Gong Y, Liu X, He W.H, Xu H.G, Yuan F, Gao Y.X, "Investigation into the antioxidant activity and chemical composition of alcoholic extracts from defatted marigold (Tagetes erecta L.) residue”, Fitoterap. 83. 481-489. 2012.

[14] Fu H, Shieh D, Ho C, “Antioxidant and free radical scavenging activities of edible mushrooms”, J Food Lipid, 9. 35-46. 2002.

[15] Lo S.H, "Quality evaluation of Agaricus bisporus, Pleurotus eryngii, Pleurotus ferulae and Pleurotus ostreatus and their antioxidant properties during postharvest storage”, Master's Thesis. National Chung-Hsing University, Taichung, Taiwan. 2005.

[16] Faujan N.H, Noriham A, Norrakiah A.S, Babji A.S, “Antioxidant activity of plants methanolic extracts containing phenolic compounds", Afr J Biotechnol, 8. 484-489. 2009.

[17] Dikilitas M, Guldur M.E, Deryaoglu A, Erel O, “Antioxidant and Oxidant Levels of Pepper (Capsicum annuum cv. 'Charlee') Infected with Pepper Mild Mottle Virus”, Not Bot Horti Agrobo, 39 (2). 58-63. 2011.

[18] Gao Y.H, Tang W.B, Gao H, Chan E, Lan J, Li X.T, Zhou S.F, Antimicrobial activity of the medicinal mushroom Ganoderma”, Food Rev Inter, 21. 211-229. 2005.

[19] Gezer K, Duru M.E, Kivrak I, Turkoglu A, Mercan N, Turkoglu H, Gulcan S, "Free-radical scavenging capacity and antimicrobial activity of wild edible mushroom from Turkey", Afr J Biotechn, 5 (20). 1924-1928. 2006.

[20] Turkoglu A, Kivrak I, Mercan N, Duru M.E, Gezer K, Turkoglu H, "Antioxidant and antimicrobial activities of Morchella conica Pers”, Afr J Biotech, 5 (11). 1146-1150. 2006.

[21] Khoobchandani M, Ojeswi B.K, Ganesh N, Srivastava M.M, Gabbanini S, Matera R, Iori R, Valgimigli L, "Antimicrobial properties and analytical profile of traditional Eruca sativa seed oil: Comparison with various aerial and root plant extracts”, Food Chem, 120. 217-224. 2010.

[22] Mondal T, Some R, Dutta S, "Studies on antioxidant and antimicrobial properties of some common mushrooms”, J Tod Biol Scien Res Rev, 2 (1). 60-67. 2013.

[23] Komemushi S, Yamamoto Y, Fujita T, “Antimicrobial substance produced by Lentinus edodes", J Antibact Antifung Agen, 23. 8186. 2005.

[24] Venturini M.E, Rivera C.S, Gonzalez C, “Antimicrobial activity of extracts of edible wild and cultivated mushrooms against foodborne bacterial strains”, J Food Protect, 71. 1701-1706. 2008. 